\title{
An Observation Method for Analyzing Operators' Routine Activity in Computerized Control Rooms
}

\author{
Lajos Izsó \\ Miklós Antalovits \\ Technicat University of Budapest, Hungary
}

\begin{abstract}
An activity analysis method was developed for studying the structure and dynamics of control room operators' activity during normal operation based on directly observable elements of the operators' behavior. The method assesses current activity along three dimensions in each 5-min period of the shift. Intensity characterizes arousal level, direction shows whether the activity is directed predominantly at the process control task, at something else, or miscellaneous. Motivation reflects if the activity is driven by intrinsic or extrinsic motivation. A case study is presented, in which 3 morning, 3 afternoon, and 3 night shifts of a Nuclear Power Plant operator crew are involved. The obtained results gave a deeper understanding of the operators' activity and also revealed an "arousal compensation" tendency.
\end{abstract}

control room operators' activity normal operation activity structure activity dynamics

\section{INTRODUCTION}

Emergencies and other extraordinary events in process control have rightfully been widely studied from the point of view of human factors, but relatively little is known about the operators' activity during normal operation, which-after all—accounts for an overwhelming part of the total operation time and from which emergencies develop. Normal operation is very often almost eventless and, therefore, boring and monotonous. Boredom and monotony-especially during night shifts-can cause potentially dangerous inattention or sleepiness. In the Hungarian process industry there have been debates about the right behavioral procedures for operators under such conditions: In certain control rooms operators are not allowed to do anything unrelated to the control task, whereas in other plants rules are more liberal.

Previous research carried out in the process industry has shown that operators strive to adjust their current arousal level to their individual optima (Izsó, 1988). It means that during understimulating or monotonous situations, operators seek additional stimuli unconnected with their process control task, whereas during

Correspondence and requests for reprints should be sent to Lajos Izsó, Department of Ergonomics and Psychology, Technical University of Budapest, Egry J. u. 1. E bldg. III. 11, H-1111 Budapest, Hungary. E-mail: <izsolajos@erg.bme.hu>. 
information overload those additional distraction activities are reduced or even entirely stopped. We also found earlier that if, for certain reasons, this arousal-adjusting is not possible under monotonous working conditions - like in the case of data entry operators or metro train co-drivers-the workers experience extreme strain and fatigue. As we noticed this arousal-adjusting tendency in the operators of the Paks Nuclear Power Plant (NPP), too, we developed a work activity analysis method for studying this phenomenon in greater detail on the basis of a systematic observation of the operators' lower-level, less complex "actions" and "operations." Actions and operations are meant in the same way as Hacker (1985) used these terms in his action theory: Actions are the smallest independent units of cognitive and sensorymotor processes that are still oriented towards consciously interpretable goals, whereas operations are action components carried out automatically without conscious control. Higher level "actions" and "acts," which are motivated by intentions and higher-order goals, are more complex activity units.

Our aim was to develop a method of providing a reliable picture of the structure and dynamics of the operators' routine behavior based on the directly observable individual motor actions and group activities. In other words, this method should provide useful information just by careful observation of the "visible surface" of the operators' routine behavior. The knowledge of the structure and dynamics of the operators' behavior is relevant for safety even in normal operation, because malfunctions and emergencies always evolve from virtually normal operation.

\section{METHOD}

Our method was developed on the basis of our previous experiences and has the following characteristics. The observable activity units are continuously assessed along the following three dimensions irrespective of their concrete content and technical reason. The intensity of an activity characterizes the arousal level and can be coded $0,1,2,3$, or 4 . The direction of an activity shows whether the activity is directed predominantly at the control task (code: $\mathrm{T}$ ), not at the control task (code: $\mathrm{N}$ ) or miscellaneous (code: M). The motivation of an activity shows if the activity is driven by intrinsic (code: i) or extrinsic motivation (code: e). In fact, the observers assess the average intensity of the activity for every crew member for every 5-min work period and also label these periods from the point of view of direction and motivation. So, to use an analogy from physics, an average intensity of activity for a given time period can be taken as a measure of the "activity quantity" produced during this period. In addition to this quantitative parameter, direction and motivation give some further qualitative information about the nature of the activity. The analysis is carried out with the help of a Unit Operator Activity Analysis Sheet (Appendix A) and an Activity Analysis Guidelines and Register of Examples (a' one-page extract can be found in Appendix B).

The minimum proposed time interval of analysis is $1 \mathrm{hr}$, which corresponds to one analysis sheet (Appendix A). This $1-\mathrm{hr}$ period is broken into twelve 5-min elementary observation periods during which at least two analyzers (observers) assess simultaneously the current values of the three dimensions. After 2-3 min of a 5-min 
period, the analyzers code their opinions, but only tentatively because they may change. At the end of each 5-min period, they fix the codes. The three-character activity codes given by different raters must agree within one scale unit; if there is no agreement in the first round they must arrive at an agreement on that very day, otherwise the analysis is not considered valid. The reason for this rule is that assessing direction and motivation is sometimes difficult for non-technologist raters. By keeping this rule in case of disagreement between raters, it is still possible to consult technologist experts to decide about the following two questions: (a) if a particular action was directed at a control task or (b) if carrying out was the operator's own decision or if - unnoticed by the rater-he actually received a request to do it. So, though at first sight conducting perfectly independent ratings and evaluating inter-rater reliability could appear a reasonable method, it has been decided that the validity of ratings is of even greater importance. So, for example, $1 \mathrm{Te}$ and $1 \mathrm{Me}$, or $2 \mathrm{Ni}$ and $3 \mathrm{Ne}$ are acceptable as the same, but $2 \mathrm{Ne}$ and $4 \mathrm{Ni}$, or $1 \mathrm{Te}$ and $1 \mathrm{Ne}$ are not.

As the activity quantity can be different in each observation period, this scoring procedure assures the necessary degree of freedom for the scales and thus avoids artificially inflated correlation coefficients. In reality, in addition to room for behavioral patterns because of the different activity quantities in case of direction, choosing code $M$ represents another degree of freedom. If the operators are not engaged in any task, the intensity of activity can be coded as 0 (Appendix B does not show it, because it is very infrequent).

Every important change in the control room must be recorded under the Remarks heading (e.g., arrival or departure of attendants, maintenance workers, technologists, cleaners, visitors, not members of the crew). This coding requires some experience, therefore, it is necessary to study the Guidelines and to carry out pilot analysis sessions with the help of an experienced observer before a real observation session.

Though the minimum possible duration of observation is $1 \mathrm{hr}$ and the "microdynamics" can be recorded in one sheet, it is desirable to carry out whole-shift analyses (using 8 copies of the analysis sheet in Appendix A). The activity dynamics can be presented both at the individual operator and the whole team level in an intensity (activity quantity)-time graph indicating either task-oriented, non-taskoriented, or miscellaneous (for team level data, see Figure 4), or the externally or internally motivated (for team level data, see Figure 8) fractions.

At individual operator level the total activity quantity is supposed to be within the individual optimum range independently from the work load. This is subject to change by several factors like physiological circadian rhythm, activity done immediately before the shift, duration of sleep before the shift, and so forth. The task-oriented fraction is expected to reflect the current work load, whereas the voluntarily generated activity quantity is a measure of compensation for the given operator's individual optimum arousal.

Application of this method does not require any specific knowledge about the technology, it can be carried out by psychologists or even-after necessary training -by assistants. Therefore, however, this analysis - though it is precise enough on its level - does not go to the depth of concrete cognitive processes, that is, it cannot grasp highest activity elements (Hacker, 1985): cognitive actions and acts. 
The method, therefore, can be used to assess the workload of real control activity during normal operation, but it is not really suitable for studying activity during emergency or simulator training, where-because of the great "event-flux"- the main point is the dynamics of cognitive processing. For simulator training purposes we developed another tool (Antalovits \& Izsó, 1996; Antalovits, Izsó, \& Jenei, 1995; Antalovits, Izsó, \& Takács, 1995; Izsó \& Antalovits, 1994, 1996), which utilizes "local knowledge" about technology.

Summarizing the foregoing, it can be stated that by the help of the method-to use Rasmussen's (i983) terminology of action regulation-only the "skill-based" regulation level can be studied, but this routine level is characteristic for most of the operation time.

\section{AN APPLICATION CASE STUDY}

In this section a case study is presented in which 3 morning, 3 afternoon, and 3 night shifts of an operator crew were involved at the NPP Paks between November 17 and December 1, 1990. The crew consisted of the following five members: Reactor Operator (RO), Shift Supervisor (SS), Turbine Operator (TO), Turbine Mechanic (TM), and Block Electrician (BE).

In addition to the data gained by the help of the activity analysis method described above, several other data were also collected like the difficulty of the current shift judged by the operators themselves and by the Engineer-on-Duty, the activity history of the individual operators' last $24 \mathrm{hrs}$ preceding the current shift as well as some objective and subjective measures of the individual operators' strain. The objective strain measure used was the visual critical fusion frequency (CFF), the so-called flicker test, and the subjective measure was the self-assessed degree of fatigue rated by the individual operators on a five-degree scale.

The following hypotheses were made in advance:

1. There exists an "arousal compensation" tendency and, therefore, in case of increasing task-related activities the operators reduce their non-task-related activities to keep their current arousal level within their optimum range.

2. As the operators use their non-task-related activities to adjust their arousal, the variability (variance) of non-task-related activity quantity is higher than that of the total amount of their activity quantity.

3. There also exists a tendency to compensate insufficient externally motivated activities by internally motivated (both task-related and non-task-related) ones.

4. As the operators use their internally motivated activities to adjust their arousal, the variability (variance) of internally motivated activity quantity is higher than that of the total amount of their activity quantity.

5. In case of more task-related activities both subjective and objective strain measure show increased values.

6. In case of more task-related activities both operators' own judgment and the Engineer-on-Duty's judgment show increased values for the relative difficulty of the shift.

To test these hypotheses data processing was carried out at three levels: at (a) 5-min periods of elementary observations, (b) 1-hr periods, and (c) one-shift periods. 


\section{RESULTS}

\subsection{General Findings}

All the nine shifts were normal, that is, no major malfunctions, breakdowns, or other extraordinary events occurred. The only unexpected experience was that the turnover within the crew was surprisingly high: Only two operators (TM and BE) were present all the time and two (SS and TO) more than half of the studied period. So, during the nine shifts we met altogether 14 operators instead of the original five, some of them substituted only 4 or $7 \mathrm{hrs}$, as shown in Table 1 . As the take-over periods, which interlap between two subsequent shifts, were completely different from the rest of the shifts because of the discussions of the outgoing and incoming crew members, only the first $7 \mathrm{hrs}$ of the shifts were included in the data processing.

TABLE 1. Current Working Periods (in hrs) of Individual Operators

\begin{tabular}{lcccc}
\hline $\begin{array}{l}\text { Operator's } \\
\text { Initials }\end{array}$ & $\begin{array}{c}\text { Operator's } \\
\text { Position }\end{array}$ & $\begin{array}{c}\text { Morning } \\
\text { Shifts }\end{array}$ & $\begin{array}{c}\text { Afternoon } \\
\text { Shifts }\end{array}$ & $\begin{array}{c}\text { Night } \\
\text { Shifts }\end{array}$ \\
\hline BR & TO & 0 & 4 & 0 \\
BT & RO & 7 & 7 & 0 \\
CF & RO & 0 & 0 & 7 \\
FA & RO & 14 & 0 & 0 \\
FG & BE & 21 & 21 & 21 \\
HG & SS & 0 & 0 & 7 \\
KA & TO & 0 & 0 & 7 \\
KB & TO & 21 & 13 & 0 \\
KF & TM & 21 & 21 & 21 \\
KJ & SS & 0 & 4 & 0 \\
SJ & RO & 0 & 14 & 0 \\
TZ & SS & 21 & 17 & 14 \\
UB & TO & 0 & 4 & 14 \\
VL & RO & 0 & 0 & 14 \\
\hline
\end{tabular}

The relationship between the whole team level task-related activity quantities for the nine shifts and the Engineer-on-Duty's judgment on the difficulties of these nine shifts in a five-degree scale was taken as a rough measure of validity. The corresponding Spearman rank correlation coefficient is .6190 $(N=9, p=.038)$, indicating that the method resulted more task-related activity quantities for the objectively more demanding shifts. Here and later, because the data are rather of ordinal than ratio scale, all the calculated correlation coefficients are of Spearman rank type excluding cases pairwise and assigning mean to ties.

Another important general result is that we were given an overall picture about the activity structure of the operating personnel. The proportion of task-related activities (as can be seen in Figure 1) during typical normal operation is rather low. For proper evaluation of this stacked bar chart it must be taken into account that operators $\mathrm{FG}, \mathrm{KB}, \mathrm{KF}$, and $\mathrm{TZ}$ spent really considerable time in the control room 
and their average mean percentage for task-related activity quantity is $6.75 \%$, for miscellaneous $12.75 \%$, and for non-task-related $80.5 \%$. Those who were only substituting in this crew may have produced relatively higher task-related activities because they were not perfectly familiar with this control room (there are three other control rooms with slightly differing devices and layout) and wanted to get informed. So, it can be stated that only about $7 \%$ is related directly to the control task and $80 \%$ is not. This, of course, does not mean at all that it is an easy job: the possibility of a malfunction or breakdown is always present and the operators' current mental strain could well be quite high even if they currently do not perform task-related activities.

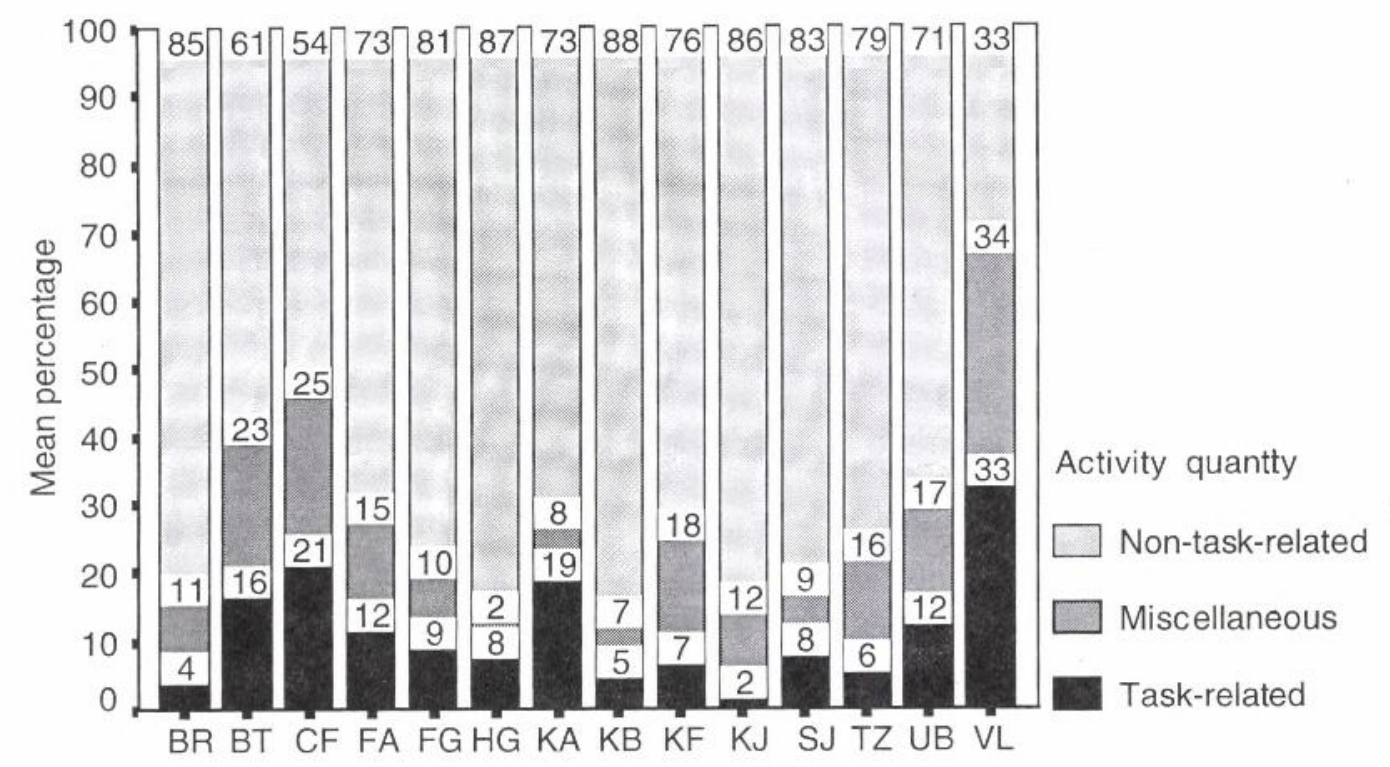

Initials of operators

Figure 1. The activity structure of operators.

\subsection{Results Concerning the Hypotheses Made in Advance}

\subsubsection{Hypothesis 1}

To test Hypothesis 1, Spearman rank correlation coefficients was calculated (a) for each single shift, (b) for all three morning, afternoon, and night shifts separately, and (c) for all available data taken together and the overwhelming majority of these coefficients were significantly negative. As illustrations, these results are summarized for all available data together in Table 2, a typical scatter plot is presented in Figure 2 (created from all available data of operator FG), and in Figure 3 the whole team level relationship can be seen in a boxplot (created also from all available data of the whole operator team). The dynamics of compensating the insufficient task-related activities by miscellaneous and non-task-related activities is shown in Figure 4 for the whole team during afternoon shift 1 . 
TABLE 2. Results of Correlation Analysis of the Relationship Between Task-Related and Non-Task-Related Activities

\begin{tabular}{lccc}
\hline Variables & $\boldsymbol{N}$ (working $\mathbf{h r s )}$ & $\boldsymbol{r}_{\mathbf{s}}$ & $\boldsymbol{p}$ \\
\hline BRSN-BRST & 4 & -.738 & .262 \\
BTSN-BTST & 14 & -.587 & .027 \\
CFSN-CFST & 7 & -.699 & .080 \\
FASN-FAST & 14 & -.519 & .051 \\
FGSN-FGST & 63 & -.607 & .000 \\
HGSN-HGST & 7 & -.823 & .023 \\
KASN-KAST & 7 & -.630 & .129 \\
KBSN-KBST & 34 & -.505 & .002 \\
KFSN-KSST & 63 & -.507 & .000 \\
KJSN-KJST & 4 & -.775 & .225 \\
SJSN-SJST & 14 & -.400 & .158 \\
TZSN-TZST & 52 & -.544 & .000 \\
UBSN-UBST & 18 & -.840 & .000 \\
VLSN-VLST & 14 & -.305 & .288 \\
\hline
\end{tabular}

Note. In the variable names the two first characters are the operators' initials; SN and ST stand for Summa Non-task-related and Summa Task-related activity quantities, respectively.

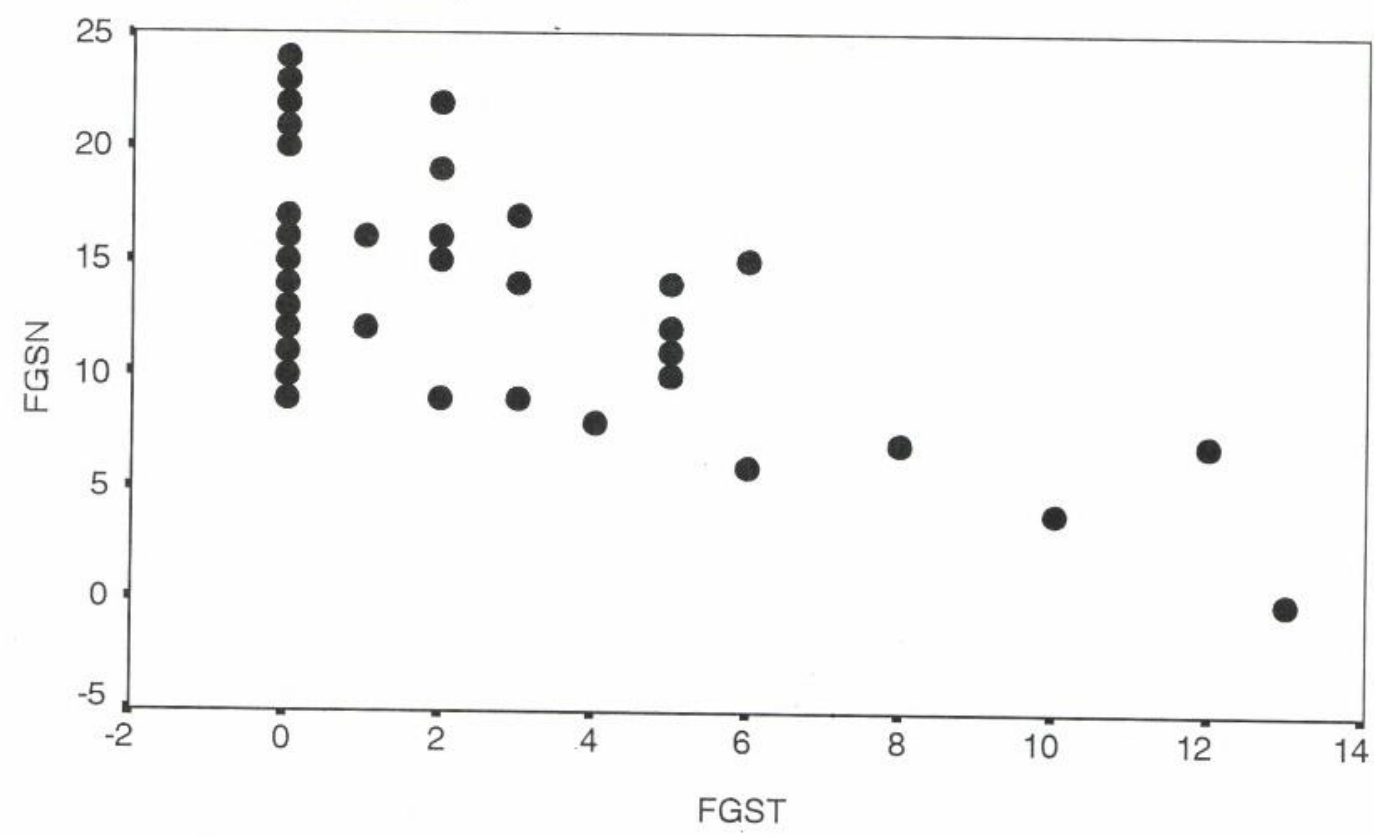

Figure 2. The scatter plot of non-task-related activities as a function of task-related activities calculated from all available data of operator FG. Table 2 shows that the corresponding Spearman rank correlation coefficient is -.607 .

The boxplot of non-task-related activities as a function of task-related activities calculated from all available data of the whole operator team. 


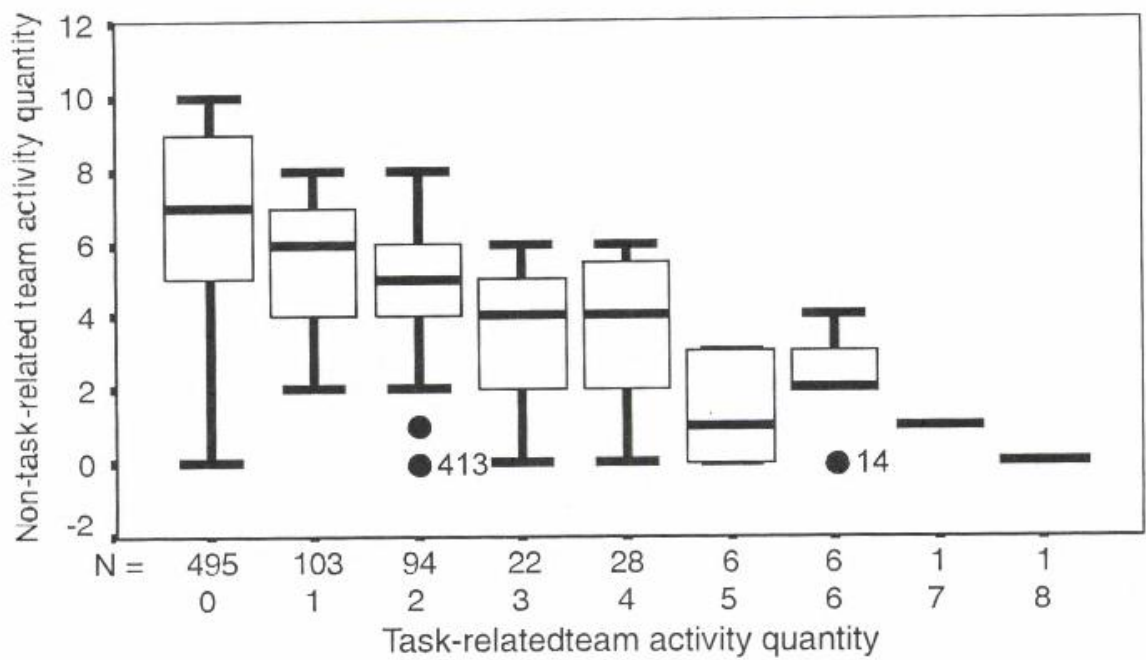

Figure 3. The boxplot of non-task-related activities as a function of task-related activities calculated from all available data of the whole operator team. Note. Relationship between task related and non-task-related activity quantities at overall team level $r_{s}=.468 p=.000$.

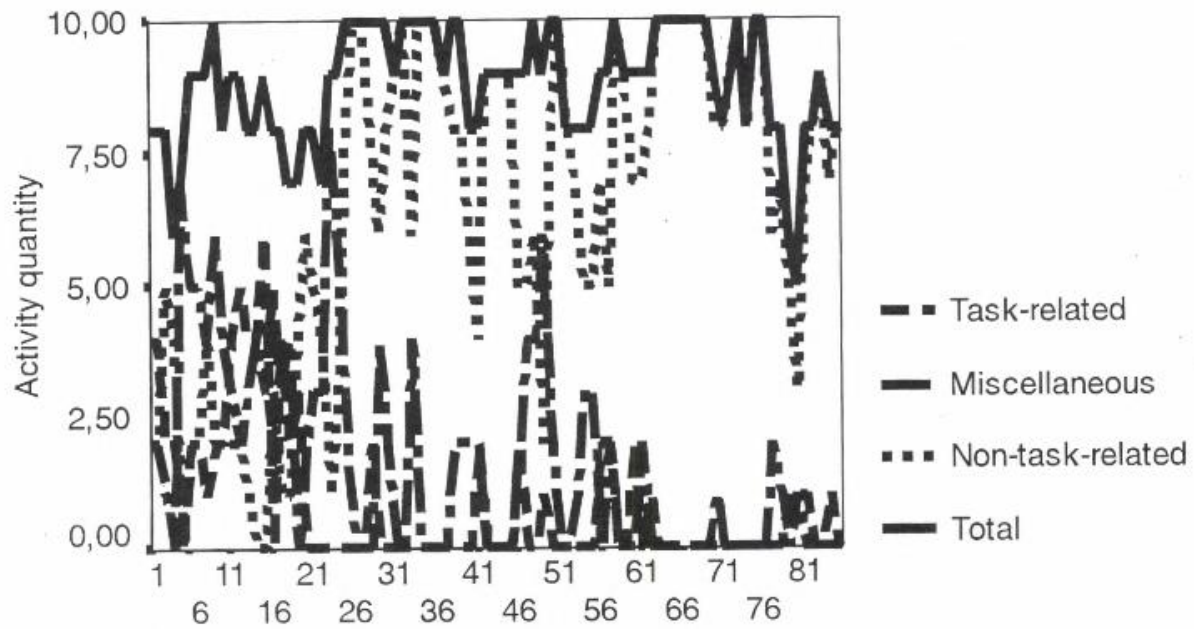

Sequence number of 5 -min periods within the shift

Figure 4. The dynamics of compensating insufficient task-related activities by miscellaneous and non-task-related activities for the whole team. Note. Dynamics of task oriented and non-task-oriented activities at overall team level (afternoon shift 1).

\subsubsection{Hypothesis 2}

To test Hypothesis 2, the variances of non-task-related and total activity quantities were compared. As can be seen in Table 3, all the variances of non-task-related activity quantities proved to be larger than the variances of total activity quantities.

Figure 5 shows this comparison graphically in the case of operator $\mathrm{TZ}$ for his all available data taken together, but separately for morning, afternoon, and night shifts. 
TABLE 3. Variances of Non-Task-Related and Total Activity Quantities per Hour

\begin{tabular}{lccc}
\hline Operator & $\begin{array}{c}\text { Variance of non- } \\
\text { task-related activity } \\
\text { quantities }\end{array}$ & $\begin{array}{c}\text { Variance of } \\
\text { total activity } \\
\text { quantities (ST) }\end{array}$ & $\begin{array}{c}\text { N } \\
\text { (working hrs) }\end{array}$ \\
\hline BR & 4.92 & 2.67 & 4 \\
BT & 37.76 & 12.53 & 14 \\
CF & 20.90 & 4.48 & 7 \\
FA & 31.19 & 15.52 & 14 \\
FG & 38.44 & 16.51 & 63 \\
HG & 18.95 & 5.81 & 7 \\
KA & 64.00 & 4.62 & 7 \\
KB & 31.96 & 20.15 & 34 \\
KF & 44.44 & 11.06 & 63 \\
KJ & 32.92 & 6.92 & 4 \\
SJ & 28.07 & 13.30 & 14 \\
TZ & 36.56 & 18.15 & 52 \\
UB & 48.81 & 9.55 & 18 \\
VL & 19.57 & 3.96 & 14 \\
\hline
\end{tabular}

Note. The result of Wilcoxon Matched-Pairs Signed-Ranks Test for the variances of $\mathrm{SN}$ with the variances of SS (total activity quantity) indicates a highly significant difference: the mean ranks of variances of ST are smaller than variances of $\mathrm{SN}$ in all the 14 cases $(z=-3.2958,1$-Tailed $p=.0005)$.

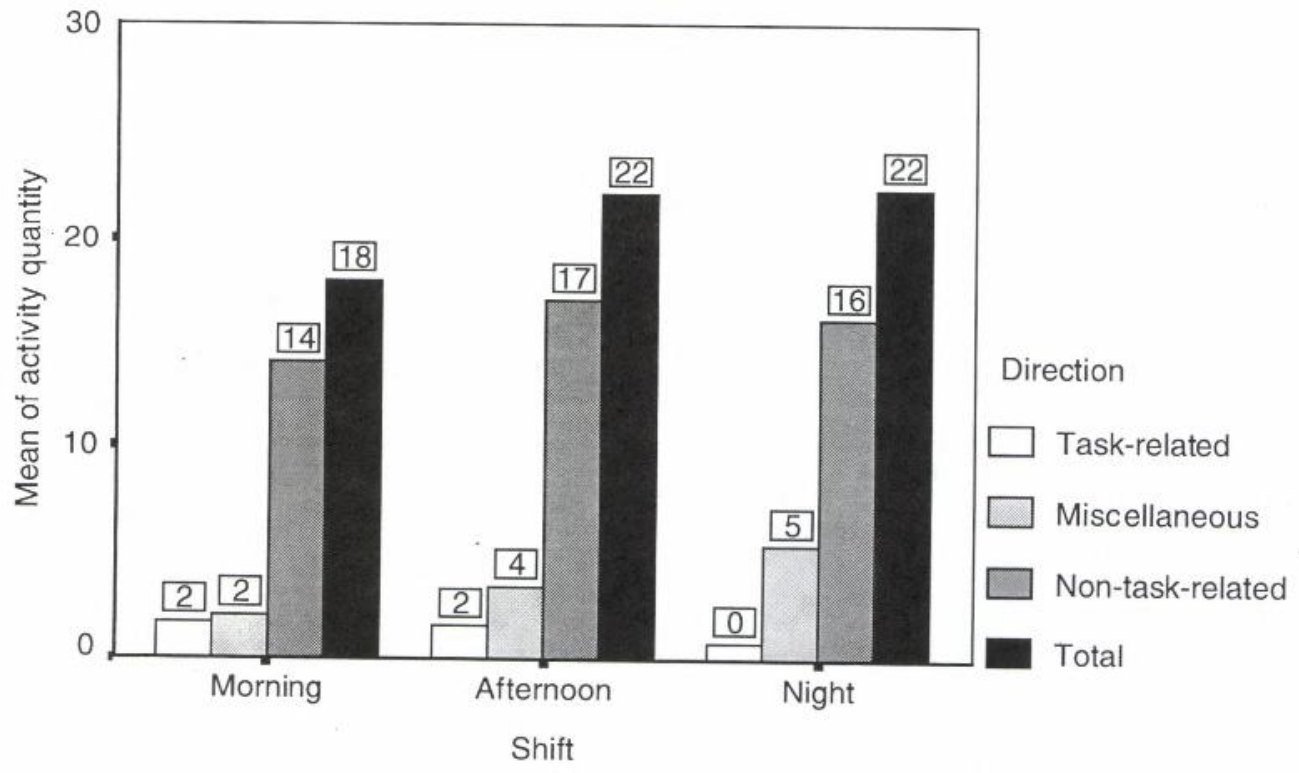

Figure 5. Comparison of variances of total, task-related, miscellaneous, and non-taskrelated activity quantities in the case of operator TZ for his all available data taken together, but separately for morning, afternoon, and night shifts.

\subsubsection{Hypothesis 3}

To test Hypothesis 3 again, Spearman rank correlation coefficients were calculated (a) for each single shift, (b) for all three morning, afternoon, and night shifts 
separately, and (c) for all available data together. About half of these coefficients were significantly negative. These results are summarized for all available data taken together in Table 4 and a typical scatter plot is also presented in Figure 6 also for all available data taken together for operator KF. In Figure 7, the whole team level relationship can be seen in a boxplot (created also from all available data of the whole operator team). The dynamics of compensating the insufficient externally motivated activity quantities by internally motivated activities is shown in Figure 8 for the whole team during afternoon shift 1. By comparing Figure 8 with Figure 4, it can be seen how the same total activity quantities are broken into different activity components.

TABLE 4. Results of Correlation Analysis of the Relationship Between Internally Motivated and Externally Motivated Activities

\begin{tabular}{lccc}
\hline Variables & $\boldsymbol{N}$ (working hrs) & $\boldsymbol{r}_{\mathbf{s}}$ & $\boldsymbol{p}$ \\
\hline BRSI-BRSE & 4 & -.778 & .222 \\
BTSI-BTSE & 14 & -.565 & .035 \\
CFSI-CFSE & 7 & -.743 & .056 \\
FASI-FASE & 14 & -.218 & .454 \\
FGSI-FGSE & 63 & -.305 & .015 \\
HGSI-HGSE & 7 & -.566 & .185 \\
KASI-KASE & 7 & -.163 & .728 \\
KBSI-KBSE & 34 & -.093 & .602 \\
KFSI-KSSE & 63 & -.643 & .000 \\
KJSI-KJSE & 4 & -.236 & .764 \\
SJSI-SJSE & 14 & -.094 & .749 \\
TZSI-TZSE & 52 & -.377 & .006 \\
UBSI-UBSE & 18 & -.413 & .089 \\
VLSI-VLSE & 14 & -.761 & .002 \\
\hline
\end{tabular}

Note. In the variable names, the first two characters are the operators' initials; $\mathrm{SI}$ and SE stand for Summa Internally motivated and Summa Externally motivated activity quantities, respectively.

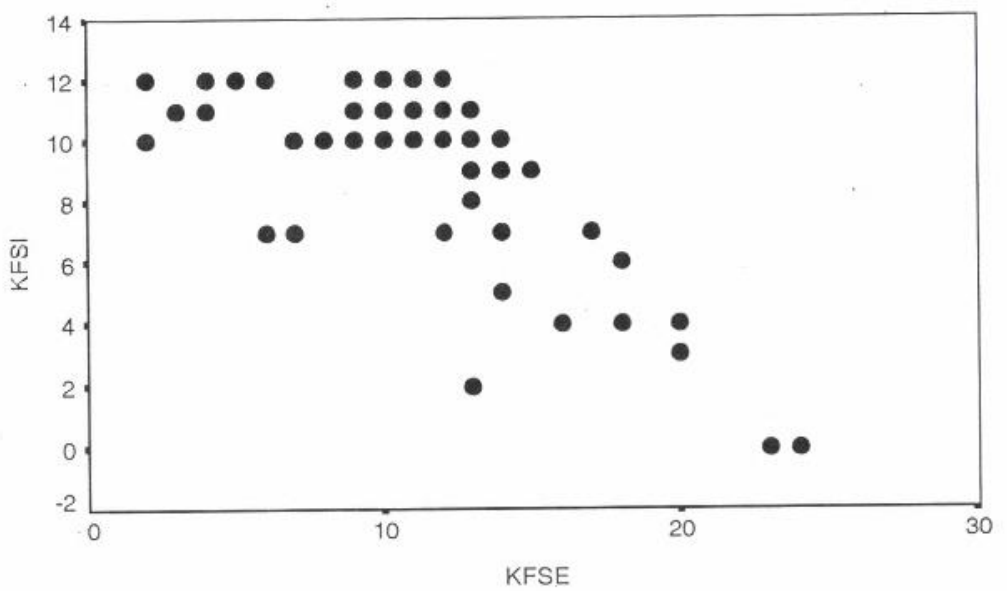

Figure 6. The scatter plot of internally motivated activities as a function of externally motivated activities from all available data of operator KF. Table 3 shows that the corresponding Spearman rank correlation coefficient is -.643 . 


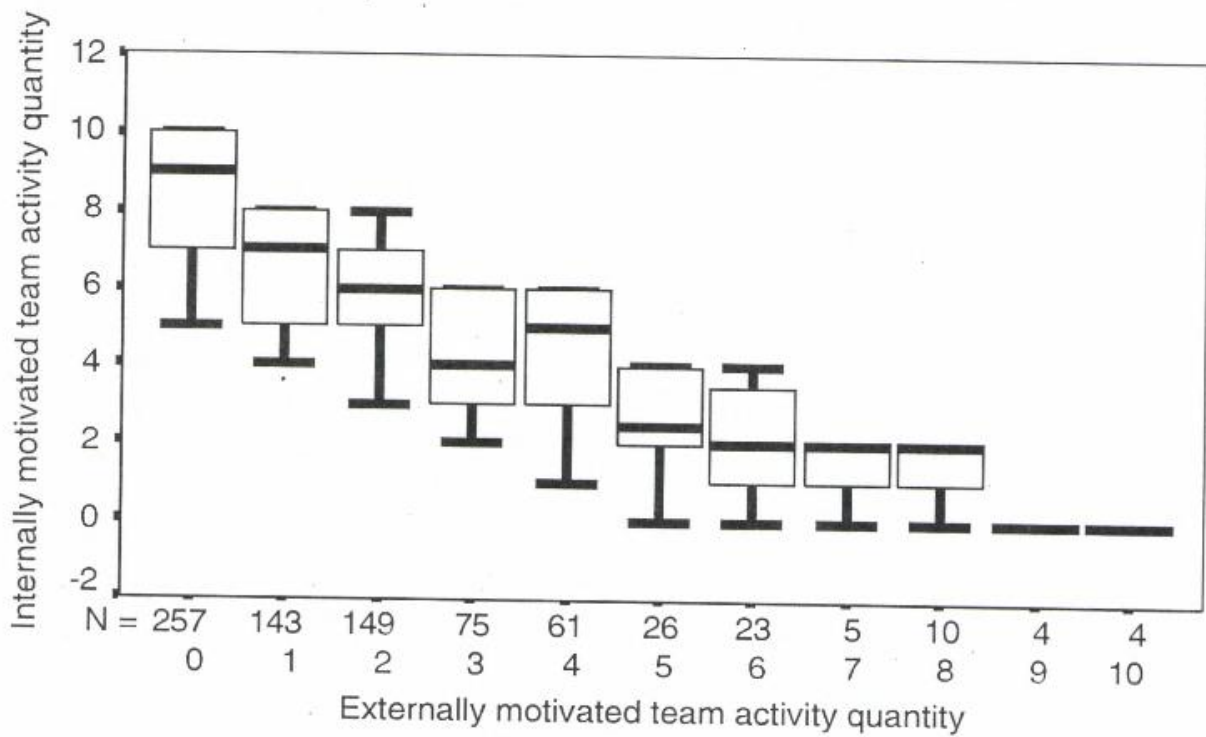

Figure 7. The boxplot of internally motivated activities as a function of externally motivated activities calculated from all avallable data of the whole operator team. Note, Relationship between externally and internally motivated activity quantities at overall team level $r_{s}=.751 p=.000$.

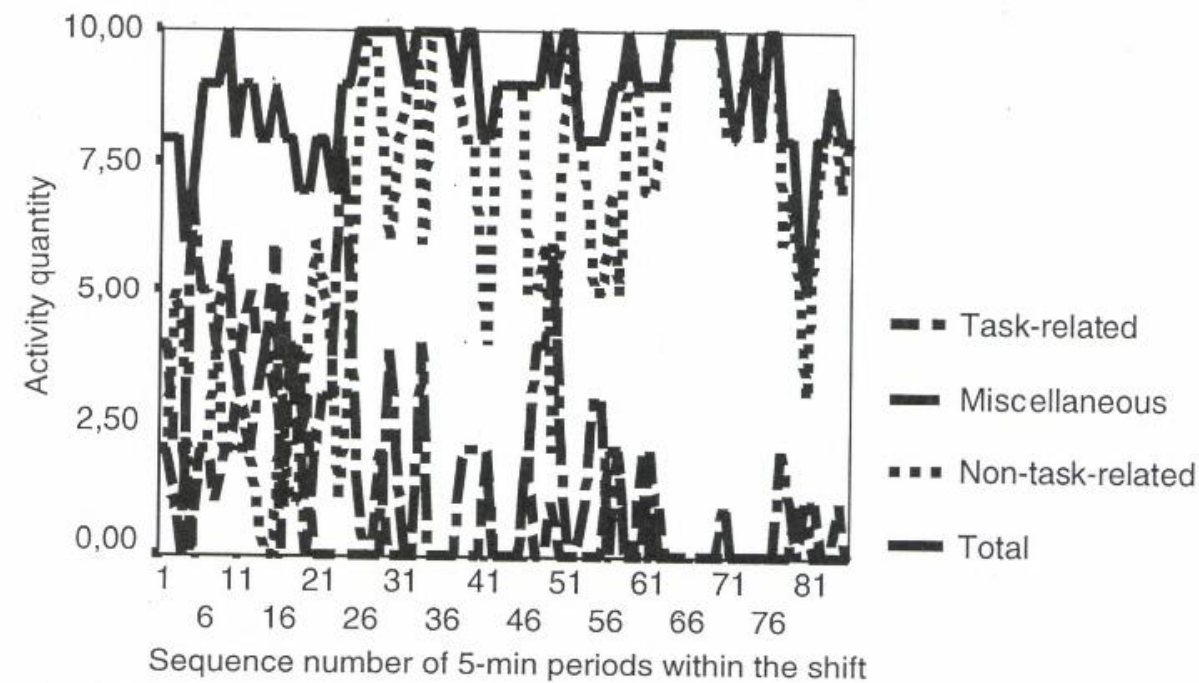

Figure 8. The dynamics of compensating insufficient externally motivated activities by internally motivated activities for the whole team. Note. Dynamics of internally and externally motivated activity quantities at overall team level (afternoon shift 1):

\subsubsection{Hypothesis 4}

To test Hypothesis 4, the variances of internally motivated and total activity quantities were compared. In contrast with the results of comparing variances of non-task-related and total activity quantities on the basis of Hypothesis 2 presented in Table 3, however, no systematic differences were found between internally motivated and total activity quantities. Our interpretation for this finding is as 
follows. Whereas the major part of group common activities-like conversationswere at the same time non-task-related ones for all the five crew members, regarding the internally or externally motivated categories some operators might initiate these activities and others might simply join them. Different operators could, therefore, receive different codes.

\subsubsection{Hypothesis 5}

To test Hypothesis 5, a detailed correlation analysis was carried out, but neither the subjective nor the objective strain measures show increased values with increased task-related activities. That is, either the sensitivity of our observation method and the used strain measuring instruments are different, or these measures are determined by different underlying processes. Similarly, there was hardly any relationship between orientation of activity or the time history of the $24 \mathrm{hrs}$ preceding the current shifts.

\subsubsection{Hypothesis 6}

To test Hypothesis 6 again, a Spearman correlation analysis was carried out for the two operators (FG and KF) who had always been present and, therefore, had all the 9 shift level data. The results are shown in Table 5.

TABLE 5. Spearman Rank Correlation Coefficients (One-Tailed) Between Shift Level Variables Characterizing Operator's Own Judgment (OOJ), Engineer-on-Duty's Judgment (EDJ) and Different Activity Data (ST, STI, SN, SNI, SS, SSI)

\begin{tabular}{|c|c|c|c|}
\hline \multicolumn{2}{|c|}{ Operator FG $(N=9)$} & \multicolumn{2}{|c|}{ Operator KF $(N=9)$} \\
\hline OOJ & EDJ & OOJ & EDJ \\
\hline ST-OOJ & ST-EDJ & ST-OOJ & ST-EDJ \\
\hline $\begin{array}{c}.880 p=.001 \\
\text { STI-OOJ }\end{array}$ & $\begin{array}{c}.150 p=.3501 \\
\text { STI-EDJ }\end{array}$ & $\begin{array}{c}.539 p=.067 \\
\text { STI-OOJ }\end{array}$ & $\begin{array}{c}.619^{*} p=.038 \\
\text { STI-EDJ }\end{array}$ \\
\hline $\begin{array}{c}.584 p=.049 \\
\text { SN-OOJ }\end{array}$ & $\begin{array}{c}-.261 p=.249 \\
\text { SN-EDJ }\end{array}$ & $\begin{array}{c}.067 p=.432 \\
\text { SN-OOJ }\end{array}$ & $\begin{array}{c}.019 p=.480 \\
\text { SN-EDJ }\end{array}$ \\
\hline $\begin{array}{c}-.584 p=.049 \\
\text { SNI-OOJ }\end{array}$ & $\begin{array}{c}-.447 p=.114 \\
\text { SNI-EDJ }\end{array}$ & $\begin{array}{c}-.496 p=.087 \\
\text { SNI-OOJ }\end{array}$ & $\begin{array}{c}-.470 p=.101 \\
\text { SNI-EDJ }\end{array}$ \\
\hline $\begin{array}{c}-.843 p=.002 \\
\text { SS-OOJ }\end{array}$ & $\begin{array}{c}-.374 p=.161 \\
\text { SS-EDJ }\end{array}$ & $\begin{array}{c}-.812 p=.004 \\
\text { SS-OOJ }\end{array}$ & $\begin{array}{c}-.212 p=.292 \\
\text { SS-EDJ }\end{array}$ \\
\hline $\begin{array}{c}-.422 p=.129 \\
\text { SSI-OOJ }\end{array}$ & $\begin{array}{c}-.112 p=.387 \\
\text { SSI-EDJ }\end{array}$ & $\begin{array}{c}.421 p=.130 \\
\text { SSI-OOJ }\end{array}$ & $\begin{array}{c}-.440 p=.118 \\
\text { SSI-EDJ }\end{array}$ \\
\hline$-.530 p=.071$ & $-.671 p=.024$ & $-.601 p=.043$ & $-.181 p=.321$ \\
\hline .082 & .417 & .123 & $=.376$ \\
\hline
\end{tabular}


The activity data gained by the observation method were defined as follows: ST $=$ Summa Task-related activity quantity, STI = Summa Task-related and Internally motivated activity quantity, $\mathrm{SN}=$ Summa Non-task-related activity quantity, SNI = Summa Non-task-related and Internally motivated activity quantity, SS = Summa Summa (total) activity quantity, and SSI = Summa Summa Internally motivated activity quantity (in these variable names, the first Summa indicates summarizing activity quantities within one shift, whereas the second one summarizing across different categories).

On the basis of data shown in Table 5 it seems that the lower the level of nontask-related and at the same time internally motivated activity (SSNI) the higher is the operator's own judgment about the difficulty of the current shift (OOJ). Taking into account also several other correlation coefficients-which are somewhat lower but still about the $p<.05$ significance level-we get the following picture. The roles of task-related and non-task-related activities in keeping the "arousal balance" seem to be different. If the operators are free to carry out all the time voluntarily initiated non-task-related activities they feel better, their arousal balance is better kept. If they are forced to perform more task-related activities, they get unbalanced and feel the shift more difficult.

It is also interesting that the Engineer-on-Duty's perception about the difficulty of shifts (EDJ) is not correlated with the perception of operators (OOJ): These two variables seem to be independent, because the Engineer-on-Duty judges solely on the basis of events observable from his central control room, whereas the operator takes into account all the current real activities.

\subsection{Additional Results}

During data processing some additional and partly unexpected results were also found not formulated in the hypotheses made in advance: In comparison with the

TABLE 6. Results of Friedman-Test Used to Compare Summa Activity Quantities of Operators FG, KB, KF, and TZ in Morning,
Afternoon, and Night Shifts

\begin{tabular}{lccc}
\hline Variables & $\begin{array}{c}\text { Mean } \\
\text { Rank }\end{array}$ & $\begin{array}{c}\text { Cases } \\
\text { (working hrs by shift) }\end{array}$ & $\boldsymbol{p}$ \\
\hline FGS (morning) & 1.05 & 21 & .001 \\
FGS (afternoon) & 2.71 & & \\
FGS (night) & 2.24 & 13 & .000 \\
KBS (morning) & 1.04 & & .001 \\
KBS (afternoon) & 1.96 & 21 & \\
KFS (morning) & 1.35 & & .051 \\
KFS (afternoon) & 2.42 & & \\
KFS (night) & 2.22 & 14 & \\
TZS (morning) & 1.25 & & \\
TZS (afternoon) & 2.05 & & \\
TZS (night) & 2.70 & & \\
\hline Note. S = Summa $=$ Total. & &
\end{tabular}


morning shifts in the afternoon and night shifts there are much higher values for non-task-related - and also miscellaneous - activities and as the level of task-related activities remains about the same the summa (total) amount of activities are also higher. For the data of those operators who spent enough time in different shifts, the Friedman-test was used to check this relationship and the following results were given (Table 6).

One comparison from Table 6-the case of operator $\mathrm{KF}$-is also presented graphically in Figure 9.

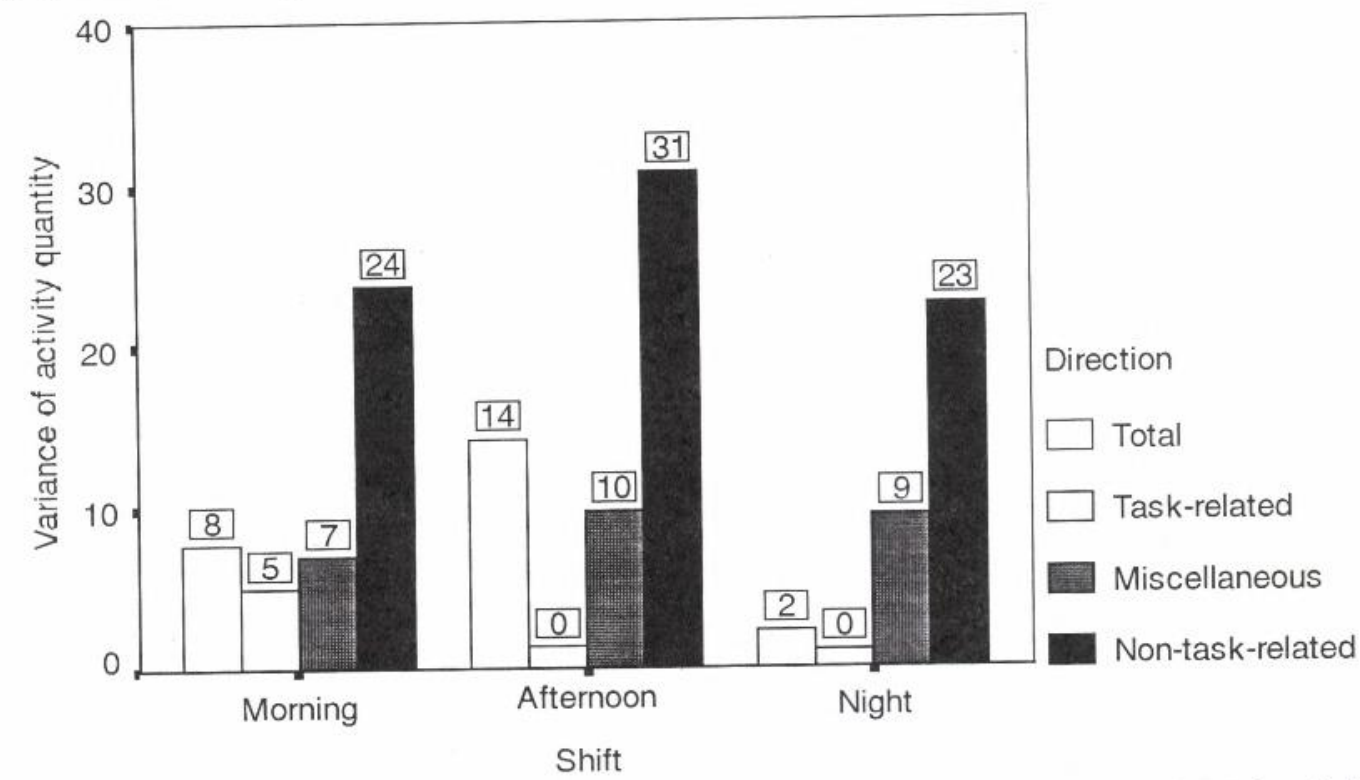

Figure 9. Comparison of task-related, miscellaneous, non-task-related, and total actlvity quantities in morning, afternoon, and night shifts in the case of operator KF. Table 6 shows that the difference between KFS (morning) and either KFS (afternoon) or KFS (night) is highly significant.

Our preliminary and tentative hypothesis for this phenomenon is the following. The background stimulus level is much higher in the morning shifts (different managers, bosses, maintenance and repair men, cleaners, visitors are coming more frequently, there are more telephone calls from outside, etc.) and in addition to that because of their circadian rhythms the operators' arousal is also higher. In the afternoon and night shifts, however, both the level of external stimulation and the operators' current arousal level are lower, therefore - as the task requirements are about the same level as in morning shifts-they feel necessary to carry out more non-task-related and miscellaneous activities to keep their vigilance high enough to be able to maintain their readiness for prompt actions if it is needed. During afterwards interviews some operators explicitly told us that they would simply fall asleep in a night shift without such non-task-related activities (taking part in conversations, listening to this and that or to the radio, ritually drinking coffee or eating, going up and down, bantering with the others, etc.). 


\section{CONCLUSIONS}

The method as a whole has been proven to be applicable, the intensity, direction, and motivation dimensions of the activity proved to be relevant by the help of which we were given a relatively exact picture about control room operators' activity dynamics both at micro and macro level during normal operation. We propose the application of the method - our its adapted version - to get a "snapshot" of control operators' activity dynamics. This study also revealed an arousal compensation tendency, which we already experienced earlier but did not study systematically thus far. Our results showed that this arousal compensation tendency is rather strong and determines well-being, therefore, the results provide evidence that it is safer to allow for operators certain kinds of non- (or not directly) task-related and voluntary activities, than expect them strictly doing nothing and being understimulated during long eventless periods of operation.

\section{REFERENCES}

Antalovits, M., \& Izsó, L. (1996, November). How to improve the crew's common understanding and norms by self-assessment during simulator training. Paper presented at the Second International Conference of HF-research in Nuclear Power Operations (ICNPO 2), Berlin, Germany.

Antalovits, M., Izsó, L., \& Jenei, C.S. (1995). New method for performance assessment in NPP training simulator. In M. Antalovits (Ed.), Proceedings of the Seventh European Congress on Work and Organizational Psychology, Gyõr, Hungary, April 19-22, (p. A84). Budapest, Hungary: Technical University of Budapest.

Antalovits, M., Izsó, L., \& Takács, I. (1995). A frame for evaluation and self-evaluation of NPP personnel. In M. Antalovits (Ed.), Proceedings of the Seventh European Congress on Work and Organizational Psychology, Gyõr, Hungary, April 19-22, (p. A14). Budapest, Hungary: Technical University of Budapest.

Hacker, W. (1985). Activity: A fruitful concept in industrial psychology. In M. Frese \& J. Sabini (Eds.), Goal directed behavior: The concept of action psychology (pp. 262-283). Hillsdale, NJ: Lawrence Erlbaum.

Izsó, L. (1988). Factors influencing human reliability in man-computer systems. Unpublished doctoral dissertation, Hungarian Academy of Sciences, Budapest, Hungary.

Izsó, L., \& Antalovits, M. (1994). What are the basic aims, criteria and methods of developing application methodology for a full scope simulator? In B. Wilpert (Ed.), First International Conference on Human Factors Research in Nuclear Power Operation, Berlin, Germany, October 31-November 2, Conference Report. Session V: Simulation, (pp. 1-2). Berlin, Germany: Research Systems Safety, Berlin University of Technology and Kyoto, Japan: Institute of Nuclear Safety Systems.

Izsó, L., \& Antalovits, M. (1996). Self-assessment during simulator training. Paper presented at the workshop on Computer supported tools for assessing and increasing effectivity of NPP simulator training organized by the Nuclear Power Plant Paks in cooperation with the International Atomic Energy Agency and the Technical University of Budapest, Paks, Hungary. December 2.

Rasmussen, J. (1983, May/June). Skills, rules and knowledge, signals, signs and symbols and other distinctions in human performance models. IEEE Transactions on Systems, Man and Cybernetics, 13(3), 257-266. 


\section{Appendix A}

\section{Unit Operator Activity Analysis Sheet}

Date:

Unit:

Shift:

Observer's name:

Simultaneous observers' names:

Beginning of observation:

o'clock

\begin{tabular}{|c|c|c|c|c|c|c|}
\hline $\begin{array}{l}\text { Operator } \Rightarrow \\
\text { Period } \Downarrow\end{array}$ & $\begin{array}{l}\text { Reactor } \\
\text { Operator } \\
\text { (RO) }\end{array}$ & $\begin{array}{l}\text { Shift } \\
\text { Supervisor } \\
\text { (SS) }\end{array}$ & $\begin{array}{l}\text { Turbine } \\
\text { Operator } \\
\text { (TO) }\end{array}$ & $\begin{array}{l}\text { Turbine } \\
\text { Mechanic } \\
\text { (TM) }\end{array}$ & $\begin{array}{l}\text { Block } \\
\text { Electrician } \\
\text { (BE) }\end{array}$ & Comments \\
\hline \multicolumn{7}{|l|}{$0-5 \mathrm{~min}$} \\
\hline \multicolumn{7}{|l|}{$6-10 \mathrm{~min}$} \\
\hline \multicolumn{7}{|l|}{$11-15 \mathrm{~min}$} \\
\hline \multicolumn{7}{|l|}{$16-20 \mathrm{~min}$} \\
\hline \multicolumn{7}{|l|}{$21-25 \mathrm{~min}$} \\
\hline \multicolumn{7}{|l|}{$26-30 \mathrm{~min}$} \\
\hline \multicolumn{7}{|l|}{ 31-35 min } \\
\hline \multicolumn{7}{|l|}{$36-40 \mathrm{~min}$} \\
\hline \multicolumn{7}{|l|}{$41-45 \mathrm{~min}$} \\
\hline \multicolumn{7}{|l|}{$46-50 \mathrm{~min}$} \\
\hline \multicolumn{7}{|l|}{$51-55 \mathrm{~min}$} \\
\hline \multicolumn{7}{|l|}{$56-60 \mathrm{~min}$} \\
\hline \multicolumn{7}{|l|}{$\Sigma T$} \\
\hline \multicolumn{7}{|l|}{$\Sigma \mathrm{M}$} \\
\hline$\Sigma N$ & & & & & & \\
\hline
\end{tabular}




\section{Appendix B}

\section{Activity Analysis Guidelines and Register of Examples}

(selections from the original)

\begin{tabular}{|c|c|c|c|c|}
\hline $\begin{array}{l}\text { Intensity } \\
\text { of activity } \\
\qquad \Downarrow\end{array}$ & $\begin{array}{c}\text { Direction of } \\
\text { activity } \Rightarrow \\
\text { Motivation } \\
\text { of activity } \\
\Downarrow\end{array}$ & $\frac{\mathbf{T}}{\text { (Task-directed) }}$ & $\underset{\text { (Non-task-directed) }}{\mathbf{N}}$ & $\mathbf{M}_{\text {(Miscellaneous) }}$ \\
\hline 1 & $\begin{array}{c}\mathbf{e} \\
\text { (external) }\end{array}$ & $\begin{array}{l}\text { 1Te Every activity for } \\
\text { the performance of } \\
\text { which the operator re- } \\
\text { ceives a request through } \\
\text { personal communica- } \\
\text { tion, telephone call, } \\
\text { audible or visual sig- } \\
\text { nal, etc. }\end{array}$ & $\begin{array}{l}\text { 1Ne Reacting to sti- } \\
\text { muli. E.g., being "half- } \\
\text { present" in conversa- } \\
\text { tion, listening to hither } \\
\text { and thither or to the } \\
\text { radio. }\end{array}$ & $\begin{array}{l}\mathbf{1 M e} \text { Every activity } \\
\text { built of predominantly } \\
1 \mathrm{Te} \text { and } 1 \mathrm{Ne} \text { elements, } \\
\text { in which none of them } \\
\text { is dominant for more } \\
\text { than } 3 \mathrm{~min} \text {. }\end{array}$ \\
\hline 1 & $\frac{\mathbf{i}}{\text { (internal) }}$ & $\begin{array}{l}\text { 1Ti Every activity for } \\
\text { the performance of } \\
\text { which is decided wit- } \\
\text { hout any urgent outer } \\
\text { pressure. E.g., record- } \\
\text { ing in the shift-book, } \\
\text { writing report, reading } \\
\text { document or perform- } \\
\text { ing any postponable } \\
\text { activity. }\end{array}$ & $\begin{array}{l}\text { 1Ni Self-stimulating. } \\
\text { E.g., beating the "devil's } \\
\text { tattoo" on the table, } \\
\text { switching the radio on, } \\
\text { lighting a cigarette, } \\
\text { beating the rhythm of } \\
\text { music by foot. }\end{array}$ & $\begin{array}{l}\mathbf{1 M i} \text { Every activity bu- } \\
\text { ilt of predominantly } 1 \mathrm{Ti} \\
\text { and } 1 \mathrm{Ni} \text { elements, in } \\
\text { which none of them is } \\
\text { dominant for more } \\
\text { than } 3 \mathrm{~min} \text {. }\end{array}$ \\
\hline 2 & $\begin{array}{c}\mathbf{e} \\
\text { (external) }\end{array}$ & $\begin{array}{l}\text { 2Te Every activity de- } \\
\text { manding concentrated } \\
\text { attention for the perfor- } \\
\text { mance of which the } \\
\text { operator receives a } \\
\text { summons. E.g., carrying } \\
\text { out orders, processing } \\
\text { urgent and accumula- } \\
\text { ted pieces of informa- } \\
\text { tion. }\end{array}$ & $\begin{array}{l}\text { 2Ne Active approa- } \\
\text { ching to outer stimuli. } \\
\text { E.g., cutting in a con- } \\
\text { versation, going to the } \\
\text { colleagues, drinking } \\
\text { coffee. }\end{array}$ & $\begin{array}{l}\text { 2Me Every activity } \\
\text { built of predominantly } \\
2 \mathrm{Te} \text { and } 2 \mathrm{Ne} \text { elements, } \\
\text { in which none of them } \\
\text { is dominant for more } \\
\text { than } 3 \mathrm{~min} \text {. }\end{array}$ \\
\hline 2 & $\frac{\mathbf{i}}{\text { (internal) }}$ & $\begin{array}{l}\mathbf{2 T i} \text { Initiating or start- } \\
\text { ing activities as well as } \\
\text { giving orders concern- } \\
\text { ing these. E.g., reading } \\
\text { off displays, interven- } \\
\text { ing, arranging for some- } \\
\text { thing to be done. }\end{array}$ & $\begin{array}{l}\text { 2Ni Active recreation. } \\
\text { E.g., going up and } \\
\text { down, going out to eat } \\
\text { something. }\end{array}$ & $\begin{array}{l}\mathbf{2 M i} \text { Every activity } \\
\text { built of predominantly } \\
2 \mathrm{Ti} \text { and } 2 \mathrm{Ni} \text { elements, } \\
\text { in which none of them } \\
\text { is dominant for more } \\
\text { than } 3 \mathrm{~min} \text {. }\end{array}$ \\
\hline
\end{tabular}

